\title{
Systemic lupus erythematosus on the Caribbean island of Curaçao: an epidemiological investigation
}

\author{
J C Nossent
}

\begin{abstract}
To determine the incidence, prevalence, and outcome of systemic lupus erythematosus (SLE) in a well delineated black population in the Caribbean basin data were collected on the disease course of all patients with definite SLE seen during a 10 year period (1980-9) using three different sources of information (hospital records, private practice records, and death certificates). Ninety four patients were identified giving an average annual incidence rate of $4 \cdot 6 / 100000(95 \%$ confidence interval (CI) 0.4 to 8.8 ), which showed little variation during the study period. Twenty five patients $(27 \%)$ died during the study period, giving a point prevalence of 47/100 000 (CI $34 \cdot 1$ to $51 \cdot 1)$ in 1990 . In women aged $15-44$ years the annual incidence $(12 / 100000$; CI $5 \cdot 3$ to 18.9) was highest, whereas in women aged 44-65 years the 1990 point prevalence rate (one in 526; CI 469 to 625) was highest. Annual mortality was $1.7 / 100000$ (CI -0.8 to $4 \cdot 2$ ) with a female to male ratio of $5 \cdot 3$. Renal disease was the most common complication, occurring in $73(78 \%)$ patients. Thus the transatlantic movement from an area with a (presumably) low prevalence of SLE (Central Africa) has been accompanied by an increase in the prevalence of SLE in the black population of Curaçao, indicating that environmental factors may prevail over genetic factors in the expression of this disease.
\end{abstract}

(Ann Rheum Dis 1992; 51: 1197-1201)

Reports on the incidence and prevalence of systemic lupus erythematosus (SLE) show a considerable variation between countries and sometimes within one country. ${ }^{1-9}$ Although a considerable part of these variations is probably due to differences in patient selection, environmental and genetic factors are also believed to influence disease expression. ${ }^{14}$ Ethnicity is considered to be one of the predominant determinants, as black subjects in the USA have a threefold increased incidence of SLE compared with white subjects, ${ }^{35}$ whereas in Chinese subjects the disease is even more common. ${ }^{67}$ On the other hand, SLE is still considered to be a rare disease (although sound epidemiological data from the area are not available) in Central Africa, which is the original homeland of many black Americans. ${ }^{89}$ At the same time as the black population was introduced into the USA, the island of Curaçao in the Caribbean basin was also populated by black people from Central Africa. They now make up more than $95 \%$ of the population on the island. This study reports the epidemiology of SLE in this well delineated black population.

\section{Patients and methods \\ PATIENTS}

The island of Curaçao is an autonomous part of the Dutch Kingdom, located $60 \mathrm{~km}$ off the coast of Venezuela with a (sub) tropical climate. Its population is estimated to be 146500 , of which less than $5 \%$ are white and which has a migratory rate of about $1 \% .^{10}$ There is one major 450 bed teaching hospital which serves the whole island. To ensure a maximum degree of completeness, information on all patients with SLE seen during the period 1980-9 was gathered from three different sources. Firstly, all medical records of patients discharged from the hospital during the study period with a diagnosis of SLE (ICD code 710.0) were reviewed; with this method 85 patients were identified. Secondly, all specialists in internal medicine (six) and dermatology (two) (there is no rheumatologist on the island) were asked in 1989 to provide information on all patients with lupus who had been in their care during that period; although most of the consultants did not keep an official diagnostic index, this provided another eight patients not identified by the hospital registry. Thirdly, all death certificates in the Public Health Department from that period containing a diagnosis of SLE were reviewed and medical records of the patients were retrieved; this provided one patient not identified by either of the other two sources.

\section{METHODS}

All patient records were reviewed by one investigator using a predefined data extraction form. Only patients fulfilling four or more American Rheumatism Association (ARA) criteria for the classification of SLE $^{11}$ were entered into the study. Information was gathered on demographic features, (cumulative) ARA criteria, initial disease activity at the time of diagnosis using the validated SLEDAI score, ${ }^{12}$ and subsequent disease course. Period prevalence rates were calculated using all patients with definite SLE seen during the study period, whereas incidence rates were calculated using only true incident cases-that is, those diagnosed during the 10 year study period. The time at which a patient fulfilled at least four ARA criteria was chosen as the time of diagnosis. For calculations of age specific rates we used the age distribution classes as given in the report by 
Siegel et al. ${ }^{2}$ Table 1 gives the breakdown figures for the general population of Curaçao, ${ }^{10}$ together with a correction factor that allows comparison of these rates with a European population which has a rather different age distribution. ${ }^{13}$

Table 1 Epidemiological data for the population of Curaçao according to gender and age classes used in this study ${ }^{\prime \prime}$

\begin{tabular}{lcccl}
\hline $\begin{array}{l}\text { Age group } \\
\text { (years) }\end{array}$ & Men & Women & Total & $\begin{array}{l}\text { Correction } \\
\text { factor }\end{array}$ \\
\hline$\leq 14$ & 22000 & 21500 & 43500 & $0 \cdot 7$ \\
$15-44$ & 34200 & 37900 & 72100 & $0 \cdot 91$ \\
$45-64$ & 10050 & 11250 & 21300 & 1.45 \\
$\geqslant 65$ & 4000 & 5600 & 9600 & $1 \cdot 95$ \\
All & 70250 & 76250 & 146500 & \\
\hline
\end{tabular}

This allows calculation of rates corrected for a European population, which has a different age group distribution with more elderly subjects. ${ }^{13}$

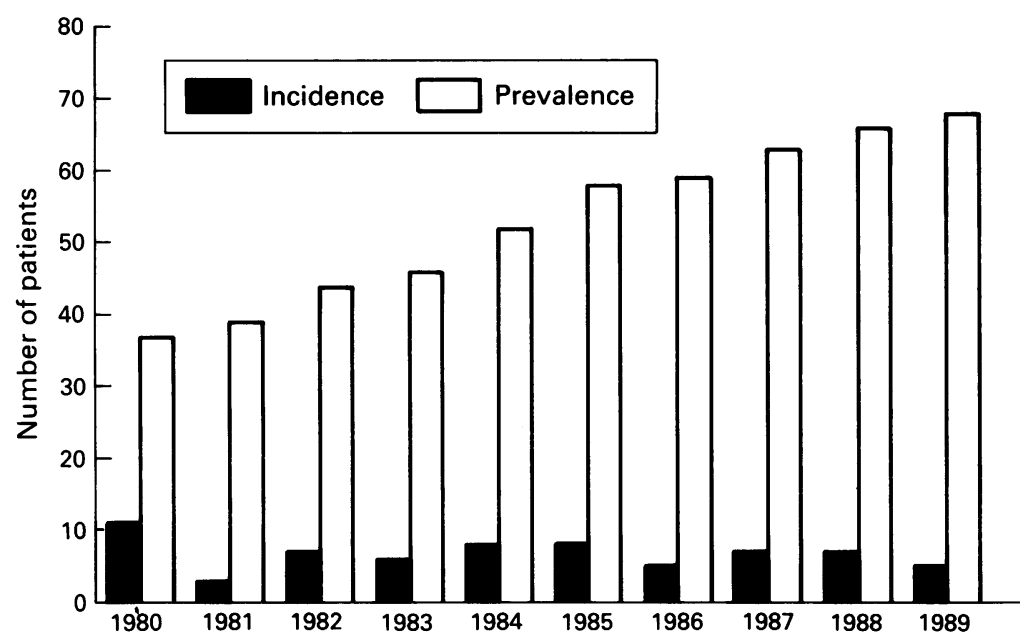

Figure 1 Crude annual incidence and (period) prevalence rates for systemic lupus erythematosus in Curaçao between 1980 and 1989. Bars indicate numbers of patients.

Table 2 Demographic features of 94 black patients with systemic lupus erythematosus on Curaçao

\begin{tabular}{lc}
\hline $\begin{array}{l}\text { No men/women (ratio) } \\
\text { Symptomatic period before }\end{array}$ & $83 / 11(7 \cdot 5)$ \\
diagnosis (range) (years) & $1 \cdot 7(0-11 \cdot 8)$ \\
Mean (SD) age at diagnosis (years) & $34 \cdot 6(14 \cdot 8)$ \\
Mean (SD) SLEDAI score at diagnosis & $13 \cdot 3(6 \cdot 8)$ \\
Mean (SD) follow up period (months) & $70 \cdot 7(69)$ \\
No (\%) of deaths & $25(27)$ \\
\hline
\end{tabular}

Statistical analysis of data was performed with the Mann-Whitney U test for differences between continuous variables and with the $\chi^{2}$ test for contingency tables. Ninety five per cent confidence intervals $(\mathrm{CI})$ were calculated using the approximation formula from the standard error, whereas survival probabilities were estimated from Kaplan Meier curves. Figures represent mean values unless otherwise stated; $\mathrm{p}<0.05$ was considered statistically significant.

\section{Results}

INCIDENCE AND PREVALENCE

A total of 94 patients were identified during the 10 year period. All patients were of African descent; table 2 summarises their demographic features. There was no significant difference in these features between true incident cases and previously (before 1980) diagnosed cases, except for the follow up period (as expected). Twenty five patients died during this period, giving an overall prevalence rate for SLE on 1 January 1990 of $47 / 100000$ (CI $34 \cdot 1$ to $51 \cdot 1$ ) at risk. Figure 1 shows the course of prevalence rates for the study period. Analysis of age specific prevalence rates by gender at the end of the study period revealed a maximum prevalence rate of $186 \cdot 6 / 100000$ (or one in 526) in women aged 45-64 (table 3). Sixty eight true incident cases were identified during the 10 year study, giving a mean annual incidence rate of $4 \cdot 6 / 100000$ at risk (CI $0 \cdot 4$ to $8 \cdot 8$ ). Annual incidence rates for the whole study period are also shown in figure 1 and show a relatively const . It level of newly diagnosed cases over the 10 ye:r period. Table 4 shows the age specific incidence rates by gender during that period. Considerable variations were found, with the lowest rate $(0.57 / 100000)$ for men aged $15-44$ years and the highest rate $(12 \cdot 1 / 100000)$ in women in the same age group.

\section{MORTALITY}

Twenty five patients $(27 \%)$ died during the study period. There was no difference in the

Table 3 Age specific period prevalence rate of systemic lupus erythematosus in Curaçao by gender, 1980-90

\begin{tabular}{|c|c|c|c|c|c|c|}
\hline \multirow{2}{*}{$\begin{array}{l}\text { Age group } \\
\text { (years) }\end{array}$} & \multicolumn{2}{|l|}{ Men } & \multicolumn{2}{|l|}{ Women } & \multicolumn{2}{|l|}{ Total } \\
\hline & $\begin{array}{l}\text { No of } \\
\text { patients }\end{array}$ & Prevalence rate $(C I)^{*}$ & $\begin{array}{l}\text { No of } \\
\text { patients }\end{array}$ & Prevalence rate $(C I)^{*}$ & $\begin{array}{l}\text { No of } \\
\text { patients }\end{array}$ & Prevalence rate $(C I)^{*}$ \\
\hline $\begin{array}{l}\leqslant 14 \\
15-44 \\
45-64 \\
\geqslant 65\end{array}$ & $\begin{array}{l}1 \\
0 \\
1 \\
4\end{array}$ & $\begin{array}{c}4.5(0.3 \text { to } 8 \cdot 7) \\
-\quad 10 \cdot 0(3.8 \text { to } 16 \cdot 2) \\
101.3(81.7 \text { to } 120 \cdot 9)\end{array}$ & $\begin{array}{r}0 \\
38 \\
21 \\
4\end{array}$ & $\begin{array}{c}\overline{102} \cdot 9(83 \cdot 1 \text { to } 122 \cdot 6) \\
186 \cdot 6(159 \cdot 9 \text { to } 213 \cdot 2) \\
70 \cdot 7(54 \cdot 2 \text { to } 86 \cdot 2)\end{array}$ & $\begin{array}{r}1 \\
38 \\
22 \\
8\end{array}$ & $\begin{array}{r}2 \cdot 2(-0 \cdot 7 \text { to } 5 \cdot 1) \\
52 \cdot 3(38 \cdot 2 \text { to } 66 \cdot 4) \\
104 \cdot 2(84 \cdot 3 \text { to } 124 \cdot 1) \\
83 \cdot 7(65 \cdot 7 \text { to } 101 \cdot 7)\end{array}$ \\
\hline Total & 6 & $8.5(2.8$ to $14 \cdot 2)$ & 63 & $83.8(65 \cdot 8$ to $101 \cdot 8)$ & 69 & $47 \cdot 6(34 \cdot 1$ to $51 \cdot 1)$ \\
\hline
\end{tabular}

Indicates rate per 100000 subjects; CI denotes $95 \%$ confidence interval.

Table 4 Age specific incidence rates of systemic lupus erythematosus by gender in Curaçao, 1980-9

\begin{tabular}{|c|c|c|c|c|c|c|}
\hline \multirow{2}{*}{$\begin{array}{l}\text { Age group } \\
\text { at diagnosis } \\
\text { (vears) }\end{array}$} & \multicolumn{2}{|l|}{ Men } & \multicolumn{2}{|l|}{ Women } & \multicolumn{2}{|l|}{ Total } \\
\hline & $\begin{array}{l}\text { No of } \\
\text { patients }\end{array}$ & Incidence rate $(C I)^{*}$ & $\begin{array}{l}\text { No of } \\
\text { putients }\end{array}$ & Incidence rate (CI) & $\begin{array}{l}\text { No of } \\
\text { paticnts }\end{array}$ & Incidence rate $(C I)^{3}$ \\
\hline $\begin{array}{l}\leqslant 14 \\
15-44 \\
45-64 \\
\geqslant 65\end{array}$ & $\begin{array}{l}2 \\
2 \\
2 \\
2\end{array}$ & $\begin{array}{l}0.91(-1.0 \text { to } 2.8) \\
0.57(-0.9 \text { to } 2.1) \\
2.01(-0.1 \text { to } 2.7) \\
5.06(0.6 \text { to } 9.4)\end{array}$ & $\begin{array}{r}2 \\
46 \\
9 \\
3\end{array}$ & 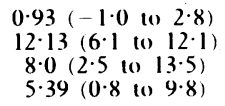 & $\begin{array}{l}4 \\
48 \\
11 \\
5\end{array}$ & $\begin{array}{l}0.92(-1.0 \text { to } 2.8) \\
6.61(1.6 \text { to } 11.6) \\
5.19(0.7 \text { to } 9.7) \\
5.26(0.8 \text { to } 9.7)\end{array}$ \\
\hline Total & 8 & $1 \cdot 13(-0.9$ to $3 \cdot 1)$ & 60 & $7 \cdot 86(2 \cdot 3$ to $13 \cdot 2)$ & 68 & $4.63(0.4$ to 8.8$)$ \\
\hline
\end{tabular}

Average annual rate per 100000 subjects during study period: CI denotes $95 \%$ confidence interval. 
Table 5 Age specific mortality from systemic lupus erythematosus in Curaçao by gender, 1980-9

\begin{tabular}{|c|c|c|c|c|c|c|}
\hline \multirow{2}{*}{$\begin{array}{l}\text { Age group } \\
\text { (vears) }\end{array}$} & \multicolumn{2}{|l|}{ Men } & \multicolumn{2}{|l|}{ Women } & \multicolumn{2}{|l|}{ Total } \\
\hline & $\begin{array}{l}\text { No of } \\
\text { deaths }\end{array}$ & Mortality rate $(\mathrm{CI})^{*}$ & $\begin{array}{l}\text { No of } \\
\text { deaths }\end{array}$ & Mortality rate (CI) & $\begin{array}{l}\text { No of } \\
\text { deaths }\end{array}$ & Mortality rate $(C I)$ \\
\hline $\begin{array}{l}\leqslant 14 \\
15-44 \\
45-64 \\
\geqslant 65\end{array}$ & $\begin{array}{l}1 \\
2 \\
1 \\
1\end{array}$ & $\begin{array}{l}0.4(-1.2 \text { to } 1.6) \\
0.6(-0.9 \text { to } 2.4) \\
1.0(-1 \text { to } 3) \\
1.3(-0.9 \text { to } 3.5)\end{array}$ & $\begin{array}{r}0 \\
12 \\
6 \\
2\end{array}$ & $\begin{array}{l}\overline{3.2}(-0.3 \text { (o } 6.7) \\
5 \cdot 3(0.8 \text { to } 9 \cdot 8) \\
3.5(-0.2 \text { to } 7 \cdot 2)\end{array}$ & $\begin{array}{r}1 \\
14 \\
7 \\
3\end{array}$ & $\begin{array}{llll}0.2 & (-0.2 & \text { to } & 0.6) \\
1.7 & (-0.9 & \text { to } & 4.3) \\
3.3 & (-0.3 & \text { 10 } & 6.9) \\
3.1 & (-0.4 & \text { to } & 6.6\end{array}$ \\
\hline Total & 5 & $0.7(-0.9$ to 2.3$)$ & 20 & $2.6(-0.6$ to 5.8$)$ & 25 & $1.7(-0.9$ to 4.3$)$ \\
\hline
\end{tabular}

${ }^{*}$ Average annual rate per 100000 subjects during study period; CI denotes $95 \%$ confidence interval.

proportion of deaths in true incident cases compared with patients diagnosed before 1980 . The mean (SD) age at death was $42 \cdot 0(18 \cdot 1)$ years, whereas the median (range) disease duration at death was 80.5 (9-214) months. Mean (SD) disease activity (by SLEDAI score) at the time of death was $14 \cdot 4(9 \cdot 1$; median $13 \cdot 5)$. Table 5 gives the age specific annual death rates by gender. Mortality rates increased steadily with age in men, whereas in women this increase was also seen, but at a persistently higher rate (nearly six times higher in the age group $15-45$ years). The mean annual death rate for all patients during the study period was $1 \cdot 7 / 100000$.

\section{SURVIVAL}

Life table analysis showed a survival probability for the 68 true incident cases in this study of $90.5 \%, 60 \cdot 1$, and $45.7 \%$ at one, five, and 10 years with a decreased survival probability for men ( $p=0.01$ by log rank test), although age group was not a significant prognostic factor.

\section{MORBIDITY}

Most patients had a prolonged symptomatic period before the diagnosis of SLE was made (table 1). Figure 2 gives the occurrence of initial and cumulative disease manifestations. The occurrence of overall mucocutaneous lesions

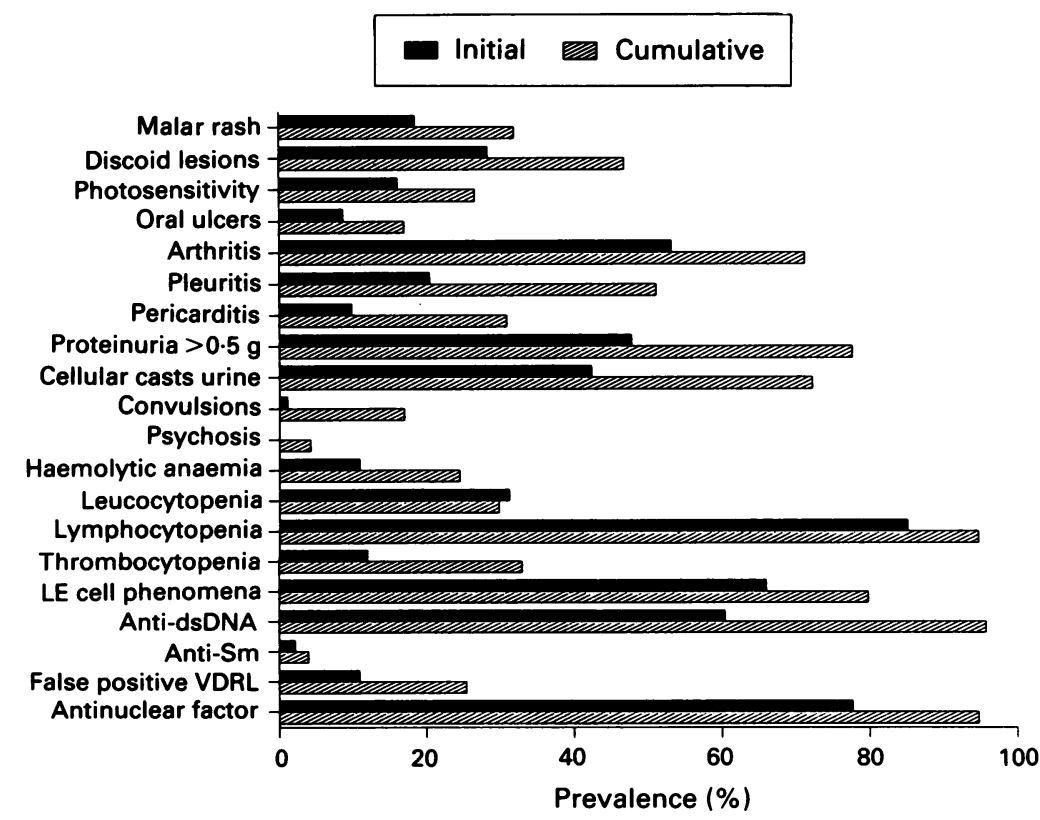

Figure 2 Occurrence of disease manifestations in 94 patients with systemic lupus erythematosus in Curaçao. Bars indicate percentage of all patients. was low at $20 \%$, whereas clinical renal disease (defined as persistent proteinuria or cellular casts, or both, in the absence of other disease) was found in $73(78 \%)$ patients (histological confirmation of lupus nephritis was obtained in only 11 patients). Patients with clinical lupus nephritis did not differ significantly from the other patients with respect to age, gender, symptomatic period before diagnosis or follow up, but only in patients with lupus nephritis did death occur $(30 \% v 0 \%$ in the patients without lupus nephritis). Renal failure requiring chronic renal replacement treatment developed in 10 (14\%) of the patients with renal disease.

\section{Discussion}

This is the first study to present epidemiologic data on SLE in a well delineated, black Caribbean population. Only the report by Wilson and Hughes in 1979 on rheumatic diseases in Jamaica has presented epidemiological data on SLE from this area; they reported the number of patients with SLE seen in an outpatient clinic during a three year period. ${ }^{14}$ Rough estimates indicated that the prevalence of SLE in Jamaica at that time was about 5-17/100 000, depending on the estimated size of the population served by their clinic. ${ }^{14}$ Our data indicate a 1980 prevalence rate of $22 / 100000$ in Curaçao. The exclusion of private patients from the study in Jamaica may account for the difference. In the period studied the highest prevalence of SLE in Curaçao was found in women aged 15-64 years; for this whole age group the rate indicates that one in 689 black women have SLE (for the age group 15-44, one in 970 ; for the age group 45-64, one in 526) as opposed to men of the same age, in whom the disease affects one in 14 285. This prevalence rate is lower than that in black women, but similar to that in white women in the USA as reported by Fessel. ${ }^{3}$ This variance in prevalence and the fact that SLE seems to be such a rare disease in Central Africa (although this statement has to be treated with caution because of the limited availability of diagnostic tools and the lack of good epidemiological data from this area) indicates that ethnicity can be superseded by environmental factors as a major determinant for the expression of SLE. Also, the annual incidence rate in this black population $(4 \cdot 6 / 100000)$ is almost identical to that found in a study in south Sweden within a study group with a entirely different genotypic make up, ${ }^{15}$ although it is lower than that in a group of black subjects in Baltimore. ${ }^{5}$ The environmental factors affecting these results are unknown; one theory relies on the immuno- 
suppressive effect of ubiquitous parasitic infections to explain the low prevalence of SLE in Africa, ${ }^{16}$ but this finding has not been expanded. Others assume that various factors (toxic, psychological) in the Western world may predispose for the development of SLE, ${ }^{4}$ making SLE a disease of prosperity. Siegel, in his landmark study, found a lower prevalence of lupus in black and white subjects in rural areas compared with those in a large city, but definitive proof is lacking. The possibility of not determining all subjects affected was a major concern in this study, as the most critical part was the non-availability of diagnostic indices from the cooperating consultants, who thus had to rely on memory to identify patients. As SLE is a chronic disease in which exacerbations may occur at any time in the disease course, most patients with lupus remain under prolonged control (although the frequency of visits may vary) and, as the island population has a low migratory rate, ${ }^{10}$ it seems unlikely that the number of patients who may have been missed by the methods used (because they were discharged or had left the island) would have significantly altered the given rates. Also, Petri et $a l^{17}$ have found an average admission frequency of 4.4 over a five year period for patients with lupus in an inner city population, whereas Pistiner $e t$ al showed that more than half of their new (private) patients with lupus in the last decade needed at least one admission. ${ }^{18}$ Thus the admission rate for patients with SLE in the first years of their disease is high and socioeconomic factors seem to influence this rate. As the per capita annual income in Curaçao is about US\$5000, ${ }^{10}$ the high frequency of admitted patients in this study is not remarkable and lessens the probability of cases being under estimated. The good overlap of patient identification (only $10 \%$ of patients identified by one source only) also supports this view.

The occurrence of specific clinical manifestations (initially and overall) of SLE in our patients and the sex distribution was similar to that in reports from Jamaica, ${ }^{14}$ Sweden, ${ }^{15}$ the USA, ${ }^{18}{ }^{19}$ and The Netherlands. ${ }^{20}$ As this study was based on patient record findings, however, it is conceivable that skin lesions (erythema may be hard to distinguish in black patients) and mouth ulcers may have been underestimated as these diagnoses are easily missed during routine investigations. Lupus nephritis was a common complication, present at diagnosis in $48 \%$ and finally in $78 \%$ of our patients. As histological confirmation was not always obtained these results may be an overestimation, but it has been reported that black patients with SLE tend to have more common and more serious renal disease. $^{21} 22$ Furthermore, the clinical manifestations of lupus nephritis have been shown to be reliable indicators for the presence or absence of renal disease, ${ }^{23}$ though they do not accurately reflect its severity. ${ }^{24}$ As renal disease is still the principal prognostic factor in lupus, this high percentage of renal disease may explain the relatively poor survival in our true incident patients. Also, the median initial SLEDAI scores (table 1) indicated a high disease activity in our patients at diagnosis, which is another poor prognostic sign as shown by Ginzler et al ${ }^{25}$ and Chang et al. ${ }^{26}$ The mortality rate in male patients in this study was comparable with the rate $(0 \cdot 8)$ reported by Siegel $e t a l^{2}$ and showed a steady increase with age, indicating that lupus did not alter the life expectancy of male patients. In female patients, however, the mortality rate was continuously higher than in male patients with a peak rate $(5 \cdot 3)$ in women aged 45-64 years and lower rates $(3 \cdot 16 / 3 \cdot 5)$ in younger and older female patients. This indicates a significant negative influence of lupus on life expectancy overall, but foremost in the young female patients, as was also found in the study in Jefferson, USA. ${ }^{2}$ Some caution must be taken in accepting this interpretation as the number of (especially male) patients was small.

In summary, this study indicates that SLE is a prevalent disease in black Carribean women aged between 15 and 64 years, with a steady rate of incidence over the last decade. Renal disease is the most common complication of lupus in these patients, and is associated with a decreased life expectancy in young women.

1 Fessel W J. Epidemiology of systemic lupus erythematosus. Rheum Dis Clin North Am 1988; 14: 15-23.

2 Siegel M, Holley H L, Lee S L. Epidemiologic studies on systemic lupus erythematosus. Comparative data for New York City and Jefferson County, Alabama 1956-1965. Arthritis Rheum 1970; 13: 802-11.

3 Fessel W J. Systemic lupus erythematosus in the community: incidence, prevalence, outcome and first symptoms: the high prevalence in black women. Arch Intern Med 1974; 134: 1027-35.

4 Christian C L. Etiologic hypothesis for systemic lupus erythematosus. In: Lahita R G, ed. Systemic lupus eryerythematosus. In: Lahita R G, ed. Systemic lupus ery-
thematosus. New York: Churchill Livingstone, 1987: 65-79.

thematosus. New York: Churchill Livingstone, 1987: 65-79.
Hochberg M C. The incidence of systemic lupus erythematosus in Baltimore, Maryland, 1970-1977. Arthritis Rheum 1985; 28: $80-6$.

6 Serdula M K, Rhoads G G. Frequency of systemic lupus erythematosus in different ethnic groups in Hawaii. Arthritis Rheum 1979; 22: 328-33.

7 Frank A O. Apparent predisposition to systemic lupus erythematosus in Chinese patients in West Malaysia. Ann Rheum Dis 1980; 39: 266-9.

8 Taylor H G, Stein C M. Systemic lupus erythematosus in Zimbabwe. Ann Rheum Dis 1986; 45: 645-8.

9 Jacyk W K, Damisah M. Discoid lupus erythematosus in the Nigerians. Br F Dermatol 1979; 100: 131-5.

10 Centraal Bureau Statistiek van de Nederlandse Antillen, Yearbook, 1989.

11 Tan E M, Cohen A S, Fries J F, et al. The 1982 revised criteria for the classification of systemic lupuserythematosus. Arthritis Rheum 1982; 25: 1271-7.

12 Liang M H, Socher S A, Larson M G, Schur P H. Reliability and validity of six systems for the clinical assessment of disease activity in systemic lupus erythematosus. Arthritis Rheum 1989; 32: 1107-18.

13 Council of Europe. Recent demographic developments in the member states of the Council of Europe. Strasbourg: the Council, 1990.

14 Wilson W A, Hughes G R V. Rheumatic diseases in Jamaica. Ann Rheum Dis 1979; 38: 320-5.

15 Jonssen $\mathbf{H}$, Nived $\mathbf{O}$, Sturfelt G. Outcome in systemic lupus erythematosus. A prospective study of patients from erythematosus. A prospective study of patients from
defined population. Medicine (Baltimore) $1989 ; 8: 141-50$.

16 Greenwood B M. Autoimmune disease and parasitic infections in Nigerians. Lancet 1968; ii: $380-2$.

17 Petri M, Perez-Gutthann S, Longenecker J, Hochberg M Morbidity of systemic lupus erythematosus: role of race and socioeconomic status. Am f Med 1991; 91: 345-53.

18 Pistiner M, Wallace D J, Nessim S, Metzger A L, Klinenberg J R. Lupus erythematosus in the 1980s: a survey of 570 patients. Semin Arthritis Rheum 1991; 21: 55-64.

19 Reeves W H, Lahita R G. Clinical presentation of systemic lupus erythematosus in the adult. In: Lahita $R \mathbf{G}$, ed. Systemic lupus ervthematosus. New York: Churchill Livingstone, 1987: $355-412$.

20 Swaak A J G, Nossent J C, Bronsveld W, et al. Systemic lupus erythematosus. Outcome and survival: Dutch experience with 110 patients studied prospectively. Ant Rheum Dis 1989; 48: 447-54.

21 Hochberg M D, Boyd R E, Ahearn J M, et al. Systemic lupus erythematosus: a review of clinico-laboratory features and immunogenetic markers in 150 patients with features and demographic subsets. Medicine (Baltimore) 1985;64:285-95. 
22 Esdaile J M, Levington C, Federgreen W, Hayslett J P, Kaashgarian $M$. The clinical renal biopsy predictors of long-term outcome in lupus nephritis: a study of 87 patients and review of the literature $Q 7$ Med 1989; 269: 779-833.

23 Nossent J C, Bronsveld W, Swaak A J G. Systemic lupus erythematosus III: observations on clinical renal involvement and follow-up of renal function in 110 patients. Ann Rheum Dis 1989; 48: 810-6.

24 Nossent J C, Henzen-Logmans S C, Vroom T, Berden J H M, Swaak A J G. Contribution of renal biopsy data in predicting disease outcome in lupus nephritis analysis of 116 cases. Arthritis Rheum 1990; 33: 970-7.

25 Ginzler E M, Diamond H S, Weiner M, et al. A multicenter study of outcome in systemic lupus erythematosus I. Entry variables as predictors of prognosis. Arthritis Rheum 1982; 25: 601-11.

26 Chang C, Urowitz M B, Gladuran D, Bombardieri C. Impaci of systemic lupus erythematosus disease activity index in systemic lupus erythematosus [abstract]. Arthritis Rheum 1986; 29: 593 . 